\title{
How customer communications and interactions become digital assets and critical resources in customer engagement - An interview with Dieter Reichert, co-founder of Censhare AG
}

\begin{abstract}
Dieter Reichert
is one of the co-founders of censhare AG and responsible for strategic planning and worldwide marketing of the censhare Communication and Publishing System. He draws on more than 30 years media experience. As founder and guiding force behind media-specific IT companies, he is a welcome guest at international meetings, fairs, conferences, strategy planning sessions and discussion groups. Reichert has won an international reputation for clear thinking, straight talking and anticipating trends. He regards censhare software as part of a unified way of life in which cooperation, sharing and communication are at the heart of the business. He has succeeded in blending science, research, mythology, personal experience and intuition into an exciting look at what the future can hold. Informed audiences will find his lectures an enlightening experience.
\end{abstract}

ABSTRACT The vision that drives us: censhare is the world's leading solution provider for the comprehensive information and process management of modern corporations and media companies. From our viewpoint, new business ideas and new impulses can only arise where latitudes are generated that enable creative and open thinking in all directions. Therefore we have developed a software system in which all relevant company information can be compiled, as well as linked and further processed without any restrictions whatsoever. We are convinced that this way of working will determine and shape company cultures, now and in the future.

Journal of Digital Asset Management (2010) 6, 232-242. doi:10.1057/dam.2010.26

Keywords: publishing \& communication workflow; integrated content platform; web CMS; metadata; content optimization

MM: We are here with Dieter Reichert of censhare. Let's begin with your personal background, starting with your name, title and career highlights.

DR: Okay, I am Dieter Reichert. I am the $\mathrm{CCO}$ and one of the owners of censhare. I have more than 20 years experience in the publishing industry, starting with typesetting.
I then worked for newspapers and magazine production. Then I changed my life and went to India to learn more about psychology, starting a few companies with a focus on social psychology, drug addiction and other related issues.
After this, I then I went back into publishing. We founded a company called Vision, becoming Europe's biggest system integrator of the Quark Publishing System. In 1999 we sold Vision to Quark.

After this, we developed a complete new concept of how to deal with information, beyond the traditional concepts of just publishing.

Our concept addresses future uses of information and the need for a communication platform - a way for publishers, agencies or general corporations to use information in communicating with customers, vendors, employees and society. 
We founded censhare on the vision that we all work and even communicate with information.

MM: Would you say a little more about censhare - where it is located, how large it is and so on?

DR: Today, censhare has about 70 employees. Our headquarters is located in Munich, Germany. We have offices in Delhi (India), London (UK), San Francisco (California), Verona (Italy) and Zurich (Switzerland).

In Germany, we have three more offices each focused on different kind of service, such as building websites, etc. We continue to grow aggressively around the world.

Initially, we came to market with a solution addressing newspaper publishers. However, we have branched out into other areas including corporations. Our corporate customers include BMW, dyson and SwissRE, automating the production of all the marketing collaterals and communications.

From the very beginning, our customers understood that we could do everything - the automated production of newspapers, magazines, websites, blogs, newsletters, microsites - as well as the automated production of traditional printed catalogs and circulars in more than 40 languages. In part, we earned our personal reputations in our previous company as Europe's largest system integrator of Quark Publishing Systems.

MM: Who are some of the more prominent or interesting customers?

DR: We have quite of few of them.

Just to give you some examples: Conde Nast uses our technology in different countries. They use our system to produce magazines such as Vogue and Glamour - magazines you might know everywhere in the world.

We have publishers in Latin America, Abril with magazines such as Veja, the second largest magazine in the world.

We have the National Magazine in London; they use our system to produce over 20 publications.

We have NEWS Verlag Austria's largest publisher.

While we have many magazine and newspaper publishers as customers, our strongest customer base lies in special interest publishers B-to-B (business-to-business) publishing.

B-to-B publishers pace the industry in multichannel publications - print versions as well as websites, microsites, e-newsletters, etc - all very much focused on communicating with subscribers, advertisers, consumers and event sponsors.

A lot of external and user-generated information goes into a B-to-B publishing and communications system.

Subscribers or readers write comments at various microsites or websites; our system collects all that information and content and shares it with the journalists and editors - thus, making all of it, the original article and its various comments, available for reuse again in any website or printed version.

In Europe traditional B-to-C (business-toconsumer) magazines are still much more focused on one-way publishing of content.

We find B-to-B companies further down the road in using information systems to engage and communicate - more than classic consumer magazines for example.

MM: How about advertising or marketing agencies as customers?

DR: We have a very interesting concept working with McCann Erickson Europe.

As one of our largest partners, McCann Erickson uses our system to connect with client companies such as General Motors also here in the US or with Opel in Europe.

McCann Erickson Europe uses our platform to communicate with their customers, all the information about their campaigns, projects, workflows, jobs and activities.

MM: B-to-B firms typically focus on account development, lead generation and partner support. On the other hand, B-to-C firms focus more on brand building, consumer buzz through social media and sponsoring, and in-store or field promotions. What have you seen? DR: From our perspective, big consumer brands with whom we work, the overall design of their material is very important. So, they emphasize a very strong integration of their brand identity and design with different layout tools - Adobe Creative Suite, Quark and FrameMaker on the print side - as well as tools and systems for websites.

We have a lot of customers using our system - BMW, Dyson GM, Opel, etc - to speed the production of printed materials in 40 languages across 60 country markets.

Technically, variation management really distinguishes our system from traditional 
content management systems - this is why our customers use our software as communication platform.

Often, a company starts out with our platform using only a few tools. As they grow and understand more about how automation works, our clients start using the next tool and the next tool after that.

They start with media asset management and then they use the variations and language management, and then they go further using the PIM (product information management) system, taking it step-by-step until they integrate all of the different modules of our platform.

MM: Excellent. This sets up a topic that I would like you to expand further: transformational content.

In particular, how a firm makes the shift from the traditional unilateral direction paradigm of publishing content to managing content-enabled experiences and customer engagement with a bidirectional flow of content, information.

Thus, transformational content is about two things: a different way of creating and managing content and a different business model for harnessing that bi-directional or multi-modal content.

DR: This is a very, very important issue. As you said, traditional publishing is in one direction and is somewhat old fashioned. So is much of the traditional marketing. A company will send one million letters via a direct mail campaign and only receive a 2 per cent response rate - this is unacceptable.

Today the consumer is asking something on the Internet. A consumer goes to a website through Google or Facebook, and says, 'I am looking for a car, which needs only 4 liters per 100 kilometers!'

This means that the car manufacturer or reseller must achieve a high ranking - first or second place - or lose the customer.

But how can you do this? You have to be involved in more than print. This means you have to have a relevant presence in many different media - websites, social networks, microsites, Twitter - and accessible by PCs, iPads or whatever's next.

It also means that you enable people talk to you, communicate with you and your partners and, hopefully, talk to other people about your product.
So it's a lot more than just nice content; we use technology to communicate, using all of the information you get from Twitter, Facebook and e-mail as conversational content as assets. MM: Ha! Most of the content that actually engages customers and makes the sale represents user-generated material.

DR: Yes, not only is it a value for you, and user-generated content help to get your product known all over the world.

Marketers and publishers must learn that content systems must be powerful enough to aggregate all this information - content from a user on Twitter is just as valuable as the content from a company's marketing department.

Corporations must learn that content may come from their customers via sites such as Twitter and Facebook or through other social channels.

By sheer necessity, marketers and publishers will need to interact and aggregate their information via one system in the future.

Basically, in the future, marketers and publishers will be one big portal of information and metadata that enables them to understand what someone is saying, how to interact and how information has to be optimized for individual users.

So you really have to understand where the data come from, what users are talking about and how users can be connected to create more value for you.

MM: Dieter, it seems to me that the first stage of transformational content is about being much more agile in creating context - or the framework for why users engage in the first place.

Context is about what experience a user, customer or consumer wants in a particular content-service set - the package of information and structure of a site or simple page.

Thus, we are talking about how we use technology to define structure and manage context for consumption.

And, as you mentioned, how we can integrate user-generated content - whether its from a Twitter stream, blogs, forums, postings of fan page in Facebook, or other forms of user-generated content - to content data store.

You suggested that transformation content begins in the content creation process.

However, I submit that transformation content begins even sooner - where we use 
technology and social networks to listen to the customer in ways that we have not done in the past and, from that listening, how we make sense of all that unstructured content and plan our newly inspired content creation processes. DR: This may be a little bit too technical for this interview. However, we believe in gathering all the information among your various social networks and websites in a way that you could share all this information with your content creators and editors.

On your website there could be an article about your product with comments from your clients about this product and related products; attached or integrated to the article could be information related the dealers of this product worldwide, and so on.

Now here's the transformational idea: All this information does not have to be in your web content management system. Rather, some of this information could be drawn from your 'semantic network' - all linked by semantic tags and appropriate permissions.

This could include a video from YouTube, enabling you to use the video in context or send it to someone on his or her iPad.

This is also very important for us. The iPad is a completely new way of how we can communicate with users. But to us everything is information.

All we have is information in a big database with lots personalization metadata; then we try to optimize the process of communication; because of all the information we have about you, about your stated or inferred interest in a product, about the editorial content that provides the context for your experience and we know which ads to serve to you.

MM: Let's put that notion of a semantic network into the domain of content optimization how one organizes content for relevance and engagement.

I want you to speak to the notion of an engagement theater, a physical or online context in which a customer engages in a conversation with the brands and perhaps friends of the brand.

In this idea of engagement theaters - which could be a website, fan page or a location-based service - consumers use the physical senses directly interacting with packaging or a store shelf or use a mobile phone or iPad application to enhance their experience or get something done.

Thus, engagement represents metaphor that describes the sum of all points of presence in a market, some physical, some digital and some hybrids; but all of those points of presence in the market need to be managed and structured so that it gives the customer a familiar and concrete experience of being in relationship with the brand.

Engagement theaters then represent three or four facets of metadata.

First, engagement theaters start with basic content metadata to describe the content as published or presented as well as the underlying assets from which the published content came. In practical terms, these metadata start their lives as marketing plans, creative briefs and communication-claims database.

In this way, semantic tagging starts in the planning and ideation process - tagging not just content but the ideas that drove the creation of the content - and specifically the meaning drives consumption contexts.

With respect to the publishing systems and content management systems for all the finalform content, the actual metadata represent two to five times more actual data than published information.

Thus, engagement theaters turn traditional content management on its head; engagement theaters use metadata and semantics to transform dumb content into personalized user experiences.

The second aspect of engagement theaters addresses how we manage advertising; how we manage a semantically tagged inventory of ads so that I can use advertising metadata to first marry up the appropriate content with the most relevant ads of an inventory for greater relevance but perhaps longer session times and greater rates of click-through.

Thus, how do we create and maintain advertising metadata as it relates to customers, preferences and consumption of the featured product or service.

The third facet about metadata of engagement theaters - what you speak about in terms of communication - entails direct, bidirection flow of information with individual customers and semantic structure of conversations, or communications metadata. 
Initially, we want to engage customers in the appropriate language - English, Spanish, Portuguese or German.

Increasingly, we want to engage that particular person in terms of a local market either in California as opposed to New York, and then perhaps to the next levels (to the extent that users have divulged or shared with us personal information) such as their particular geographic location and their willingness to entertain mobile ads or inducements.

More to the point about actual conversations, we sustain engagement through conversations that have distinct semantic structures, patterns and sentiments.

So how do we begin modeling those conversations in metadata?

Finally, the fourth aspect of engagement theaters - about which I would like you to comment - entails the need for customer personas with a more detailed data-based description of who they are, what they want and how they want to be served.

So, now we are talking about four sets of metadata: content, ad inventory, conversations and user-consumption personas.

Where in all of that would you like to start? DR: Advertising metadata can add relevance to content, generating a greater lift as well as engagement feedback - who wants to know what.

Then we can start looking at how to organize a context of consumption for various expressions of content.

However, using those four facets you just summarized, it seems to me, sets up a number of challenges.

I am not sure that many companies have even started to solve, or even begun to think through how to solve that optimization goal.

Let's start with what I believe has already happened with content management of advertising information.

Many firms want to add product information to this mix, making it even more complex, not just information about your own products but other products of your business ecosystem or semantic network.

Detailed user personas in Germany - of the sort you suggested - would meet a lot of resistance.

However, a better understanding of a person, what are their interests, what do they love doing, what do they spend money on and so on helps companies better serve this person.

Businesses will continue working hard in the future towards better understanding of customers.

However, better customer insights means that you will have to change some aspect of your business, or you have the ability to change your company - which starts with communicationinteraction repositories.

These communication-interaction repositories will help firms better understand how your four facets of engagement theaters work together automatically, dynamically.

If you think further about it you will understand that software - communicationinteraction repositories - is key to drive the business in the future.

Think about Amazon. Everybody knows you bought a book on Amazon about a dog, you go to the web site, you click, and you get a web page directly connected to what you have bought, what they know about you, and what you have done on your last 10 clicks.

So this is the business we all become in the future. It is driven from the customer.

This means if consumers use an iPad to communicate to your firm, you must deliver content - advertising, digital goods, product shipping and logistics information, and editorial from your content team as well as content or services from external partners.

So if you think about content structure and your company, you will understand that the existing structure of your company may not work any longer.

We talk about a completely integrated system or integrated content platforms that enable executives to use their information and content to redesign their firms - they can think about their company and how to better organize its resources around the customer.

Today, the lack of an integrated content platform forces many executives to talk in terms of different departments, countries and cultures; all this is in the hands of different managers.

If you had an integrated content platform, you could get everyone to the same table and enable them to work through a new business concept, in a new structure.

It's a lot easier for new companies like Amazon to innovate a new business structure 
than a firm with over 100 years of history and embedded systems.

We have companies in Europe, especially in the newspaper industry, that say 'It's better to let this company die and start a new one because we cannot go through a change-process in peoples' minds'.

We understand this; we understand what you have to do, that you are not able to change the company.

When we talk about corporations, we find it easier to discuss business or content transformation, because they are much more business-driven.

Most publishers today believe that content and circulation databases are their real value. While that remains true in part, publishers must understand the reader's relationship with content AND the people who create and edit the content are just as important for their business in the future.

MM: As we wrap up the discussion of transformational content, would you speak to the emergence of a new kind of marketing service firm - what I have called else the nextgeneration ad agency or customer engagement agency - and how they are closing the gap or breach between major brand marketers and traditional ad agencies, or how these new agencies engage customers throughout a customer engagement life cycle.

Would you speak to that next generation agency?

DR: This is a difficult. I think that publishers are the agencies of the future.

MM: Exactly, I could not agree more.

DR: We have found that publishers around the world understand more about corporate publishing than most corporations themselves.

I think it is very interesting that publishers have begun to offer more and more publishing and customer communication services to corporations. These publishers are delivering higher-quality editorial content - that enables businesses to sell and support their products than most corporate marketing and service groups.

I believe that publishers can really exploit the situation today, becoming more a content and digital-services provider to corporations worldwide.

Publishers already have very good content, journalists, content aggregators and content infrastructure - publishers can use their expertise in content to help client-corporations market and support customers worldwide.

MM: Ha! Traditional publishers distinguish themselves from marketing people by understanding the sustainable value of news and analysis and avoid the mistake of marketing B.S.

The editors at traditional publishing groups also understand the mood of a market and the voice of the customer - how to stay relevant and how to engage with integrity about the value of featured product or service.

The editors know how to delete the stuff that rings hollow or untrue - where many marketing firms or their clients cannot bring themselves to edit out the B.S.

DR: I would say in the future people will understand more and more about the truth of a product - so there will not be so much marketing 'blah, blah, blah' any more.

That's the reason why I changed my company - we do not have a marketing department any more. I changed it into a communication department, because we communicate, not market.

This will make a big difference. In the future, a communications group will be responsible for what I would call a digital reputation.

In publications, we will rely on the digital reputations of the author of this article or the creator of a product, deciding whether or not to learn more or even buy it.

We believe that companies have to learn how to be more honest in their communications. News or rumors of lies and deception just spread too quickly today.

MM: An assumption inherent to what you just said emphasizes that communication starts with listening.

Let's discuss how firms use social media monitoring as a listening tool, using buzz reports and content analytics to better understand such things as the mood of the market (what people are saying about the market category and the various products in the category), the voice of the customer (what customers are saying about your product or service - what they like, do not like, about which they are confused) and, then the last one, the patterns of engagement (as users, has their activity intensified, is it trending positive or negative, or are we inducing apathy?). 
Thus, the summarizing of semantics of usergenerated content can provide the basis of having a conversation in the first place.

Before a firm can really communicate, before consumers will even care to engage in conversation, someone at the firm must first demonstrate the wanting to engage; they must actively listen to what the consumer or consumers actually said and respond in a natural and authentic way.

In terms of communication-interaction repositories, this will show up by keywords and phrases that resonate with the consumer.

More systemically, this will manifest as what I have heard in the industry as digital body language - a set of behavioral responses to show that one I am listening, I am in relationship and I care about what you are saying.

DR: Exactly. We know companies who have built their business just using Twitter; they do it by listening to their customers.

I even know of companies doing what you call 'support' completely on Twitter; it is completely open. And I think this is part of the future; we have nothing to hide anymore; it's just something companies have to learn.

Most companies have nothing really to hide anyway - everything is already so public anyway. You know, we are not in China. There is no wall.

Basically, we have to learn to deal with the reality that our customers, clients and trends remain wide open and available to anyone who cares to know about us.

Transparency means you have to be authentic and responsive - a big lesson because much of marketing has not been very authentic.

Marketing trends to just make up something plausible. Then they drive customers to believe it.

I truly think that only real products that truly meet the needs of customer will survive and have lots customers willing to share their experience.

This will require the use of integrated content platforms - where you can manage all these communication threads and discussions.

Now this is all pretty abstract, but at the same time we talk about an editorial system with digital asset repositories, product information managers, etc.

However, we must think beyond isolated systems.
Rather, we're much better off with one platform for content information and contextdriven metadata of social networks - what you have called 'communication-interaction repositories'.

However, if we continue to talk like this, the CEO may not understand. Therefore, we will use words like PIM, Web CMS, editorial system and so on - all familiar terms from the past that really become part of integrated content platform.

In our system, we have all these types of information organized in a way that everyone in the firm can talk to each other; you can use the system in the workflow that you like.

You can prepare management reports and at the same time you create microsites and catalogs - just find the information that you need, organize it into more useful formats and publish it in a professional way.

MM: Let's see if we can summarize the key ideas of transformational content.

First, transformational content is all about providing meaningful brand or user experiences at all of the major points-of-presence in the market, physical, digital or mobile.

Second, a meaningful experience requires a well-defined and managed context for engagement and consumption - publishing endpoints and points of presence in the market.

Third, each point of presence comes back to a specific creation and publishing workflow and an integrated content-publishing platform (that supports or enables content creation and publishing workflows).

Fourth, such a platform is more than a set of application modules; rather, this platform manages all the information as data in a database or data store, making any piece of data available to any service of the platform.

Fifth, setting up the platform entails configuration of pre-existing web-based services of the platform, eliminating the need for custom development, programming and other things that increase the total life cycle cost of the platform.

Sixth, the platform incorporates usergenerated content, giving content and engagement planners access to a communication-interaction repository (that organizes the mood of the market, voice of the customer and the semantics of conversation and engagement). 
Seventh, we manage each meaningful unit of data or content as a digital asset - everything gets tagged with metadata.

Finally, this means that we must, therefore, create content or information at the smallest atomic level - different kinds of digital Lego pieces that automated publishing tools and systems can mash-up and create entirely new products in seconds or minutes and not hours or days.

DR: I think you understand our product perfectly. We enable our customers to create and manage content or information in a very atomic way and make it available to other users in the most accessible and useful forms, whether they are journalists, product managers, digital marketing manager or content specialists running microsites.

MM: Would you expand on the idea of product and marketing information database or repository? I have begun to refer to this as a communications and marketing-claims database that marketing organizations can use to manage all of the copy-written text that they plan to make public. The term claim in this context refers to the fact that the claim entails an often lengthy development process, starting with a creative brief, copy-concept treatments, many rough drafts, and an extensive and documented approvals process that probably included legal, compliance and risk officers.

DR: censhare is a collaboration platform, which means that we have implemented workflows, scheduling and, in a worldwide context, variation management for workflows in 50 languages.

For some of our clients, this means that 1000 people can work on marketing collateral.

It also means that something will be printed in 40-60 countries; there is a lot of logistics behind it.

So, we have a robust schedule management component supporting 1000 people around the world - the system must know when every asset has to be available and accessible to whom - the next person to work on the asset or to approve it along the way to being integrated in compound documents or web pages.

This type of schedule management requires that everything relates to functional rules in the platform.

We know that an organization already owns 'free content' that they can use; but accessing this free content requires well-defined business rules and workflows that enable users to use the information in a way that's safe, secure and consistent.

MM: I want to move to the next topic and see how you might develop it.

As we all know, the iPad has come to market and, in just a few short weeks, Apple has sold millions of iPads.

Would you speak to the iPad revolution - or what I think is a revolution - and the early content categories or markets in which iPads will do especially well - and perhaps make the case for filling the demand vacuum with transformational content.

DR: In my opinion, the iPad is not as important as an iPod.

The iPad is important as another tool to communicate in an entirely new way.

The iPad is not a computer. Basically, I consider it as an entry-level communication and content presentation device - that people can use to read, look at pictures, view movies and access online data.

Basically, it is a communication tool that offsets or eliminates the need for a computer.

It is just like an electronic piece of paper; we use it to communicate with others.

It means that customer using censhare already have content ready to deliver to the iPad user, either as a static web page or dynamically assembled information.

You get static content as you can see today at New York Times or Time magazine - where you just get independent pages delivered to you via an app or as dynamic content of exactly what you are interested in.

To me, static pages are a poor way of working with the iPad - the tool offers so many dynamic possibilities in delivering content but also communicating with its users.

I believe that the iPad will become a perfect tool for teaching in schools, training teachers in new way of engaging students, communicating among children, parents and teachers, and selling customized text books and learning aids.

Basically, we consider the iPad a collaboration tool; therefore, it is perfect for our markets and exactly what we are looking for. It offers a newfound hope for publishers.

MM: Yes. I can envision college and high school textbooks as one of the first billion-dollar content categories for the iPad. 
Transformation content would allow book publishers to rent digital textbooks, instead of having to sell new ones in markets already flooded with used text books and rentals.

More to your point of using content to communicate, I see an even more interesting part of renting a textbooks: It requires a pretty extensive subscriber database record with your full name, address, age, topics that you have study or plan to study and so on.

So, the subscriber profile could easily become engagement persona, setting up all kinds of revenue opportunities - supplemental content, self-directed quizzes, correlation of your quiz results to grading averages, prompted suggestions for remedial study materials, ad hoc online study groups, and fee-based or sponsored tutoring.

As a publisher, you would know that the rented textbook disappears at the end of the semester, thus taking otherwise used inventory out of the aftermarket - thus eroding the power of a used text market.

So, iPad textbooks will not just create content footprint but enable you to create service footprint.

Thus, transformational content within the context of iPad is really about content monetization and customer engagement.

The iPad enables customers to share progressively more information about them, thus earning discounts; the publishers get better insights as to what connects and what to build next.

This of course requires a publisher to have provisioning platform with agility, content and business rules to provision layers or progressive layers of content and services - all based on permissions and roles of the individual users. Can you speak to that?

DR: You know again, everything you are telling now comes back to information - which means the user information to me.

So, I know what his profile is and his profile can change because as human beings we grow, change or just fickle some times.

MM: Unless there's something we do yet know about the real iPad infrastructure, you almost make a case for not doing an app.

Apps do not let you collect a lot of information about its users. However, if you publish information for an iPad with a browser, you can insert all kinds of data-collection forms; then I can capture a lot more information.

Of course, this will require a robust provisioning system for content and datacollection forms; upstream it will need a great editorial and asset management system, but you'll also need great customer-information management system that tracks the evolution of our relationship over time.

DR: Absolutely. This requires two things. First, you will need a customer information/ relationship management system - a way to define the data structure of a relationship and, of course, who said what in the relationship.

Second, you will need information in your database that assist you in making a new business case, creating new relationships with other information you have already in your database, or sharing with another company.

So, I would like to push this idea a bit further. A customer information/relationship management system is no longer only your own company or individuals that communicate for your company.

A customer information/relationship management system is the semantic network of your company with a larger business ecosystem and social networks of stakeholders.

The content of partners is relevant to you. I mean Google shows us how this works. It is context-driven information; today, I mostly get very static content, but in the future, the content will be completely dynamic.

In my understanding, Google remains very connected to user profiles in their cloud profiles derived from all of your searches, content analysis of your Gmails and configured feeds of your iGoogle.

In the future we will learn more about how search result pages will trigger dynamic content at Google-connected websites.

MM: So, let's shift to one more case. Many companies have invested tens to hundreds of millions of dollars in content - communications, marketing, customer support, training, etc.

So, making content more transformational more fluid and agile - makes a lot of sense.

This supports the business case for consolidating content in integrated content management platforms and communicationinteraction repositories.

Would you walk us through how you see your platform integrating with the other popular 
systems such as Sharepoint, existing web content management systems and legacy enterprise content management systems or records management system?

DR: I say throw them away. Okay, by saying this I clearly know this is impossible. Why do I say is this, you must throw them away in your minds - in how you think about content and communications.

MM: Let's already stipulate that as firms move forward, they will retire legacy systems and integrate existing systems to an enterprise web services platform.

Let's say a customer has made huge 2010/11 commitments to a worldwide rollout of Sharepoint, using it as a collaboration and content platform for various teams and projects.

In your mind, how does Sharepoint fit into your configuration?

DR: Today, and the reality today means that there are a lot of different systems installed inhouse - and we have to respect that.

Because we must plan for the future, let's use an example of customer companies who first start with digital asset management.

Why, because they have another collaboration system like Sharepoint, Lotus Notes or whatever.

For us, it is only important that the customer have a solid foundation for managing reusable content - digital asset management.

As customers create reusable content, they need to store it in a way that they can connect this content with other systems.

This means that firms need to put a content governance scheme into place, using a system such as ours.

With reusable information and content in a collaboration platform, they have already secured part of the future: they made their information accessible, governable and reusable.

From there we can connect to any system.

We have a very strong interface and web service integration with Sharepoint: information flows in a bi-directional fashion.

Our larger customers use our content workflow management capabilities, integrating finished content into an existing environment, portal or project room.

Because what you say or communicate in one country needs to change for use in other countries; sometimes it is different in the country, so you will need a way to keep track of all the variations.

MM: I suppose that also means that if I can have access to my corporate e-mail account, then I can access to this information system and workflows with a single sign-on and authorization.

DR: That it is a standout for us, this is normal. We do this with all our big clients; but it is only one part of our integration.

Before we started censhare, many of us worked at one of Europe's large system integrators - all we did was integrate systems, and I can tell you, I think I know all the names of all the software worldwide with which you can integrate in a system like ours. And, it is very important to do so.

MM: Can you then perhaps as we start to wrap up here, take us through some of your customer experience in terms of how they organize or mobilize internally to make this change this migration?

DR: You know there are many, many different stories. Let me use BMW. They came to us because they had a problem managing their marketing material in 60 countries in more than 40 languages, print every year.

After they implemented our system with their existing personnel, they could publish in more languages four times a year, creating more market-specific and customized pieces.

They already create two million assets each year, and 1000 people are working on their marketing collateral.

BMW does not publish their websites with our tools; even though they could they do not because they have too many web CMS installed worldwide. This is one story.

Another example comes from a publisher that asked us to automate everything. They have content that will be delivered in a newspaper, a magazine, a website, microsites and a newsletter.

SwissRE, one of the biggest reinsurance companies in the world, is another censhare customer. With them we started by showing them media asset management. Then we showed PIM and then we showed them workflow - and you know in 3 hours, more and more people came into the room because the CEO called them.

He said look at this, look at this, and a few days later, we had the decision from the board to buy the whole system - because they 
understood that for the future they need a platform where they can start with media asset management to prepare annual reports, and then step-by-step, in the direction of having one platform for information.

MM: So, on that note, do you have any final comments with which you would like to leave us? DR: I would conclude by saying that our system is one part of the business of the future - that also includes CRM, ERP and enterprise marketing platforms.

These three systems should talk to each other and communicate with each other all based on rules and business polices. If you are able to do this, then you can develop and execute campaigns all over the world within 1 hour, creating automatically micro-sized ads, newsletters that are sent out to the dealers or retailer.

MM: So, in our next conversation, we can examine demand management platforms or demand-side platforms, ways of managing the demand side of an overall market, emphasizing customer engagement.

DR: Excellent. I look forward to it. And thank you for the time today. 